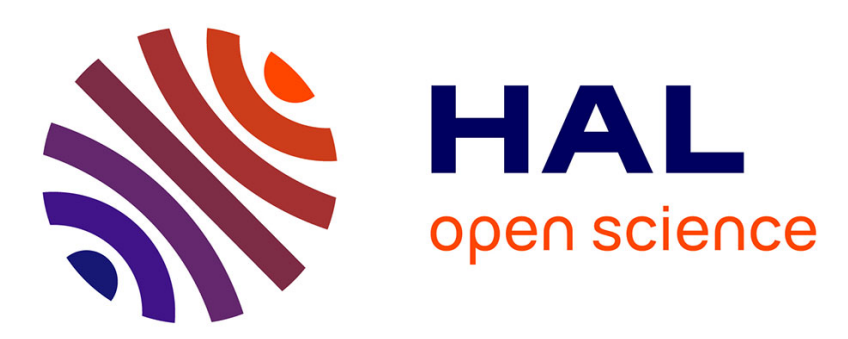

\title{
Voltammetric behaviour of cationic redox probes at mesoporous silica film electrodes
}

\author{
Deomila Basnig, Neus Vilà, Grégoire Herzog, Alain Walcarius
}

\section{To cite this version:}

Deomila Basnig, Neus Vilà, Grégoire Herzog, Alain Walcarius. Voltammetric behaviour of cationic redox probes at mesoporous silica film electrodes. Journal of Electroanalytical Chemistry, 2020, pp.113993. 10.1016/j.jelechem.2020.113993 . hal-02484251

\section{HAL Id: hal-02484251 \\ https://hal.univ-lorraine.fr/hal-02484251}

Submitted on 26 Nov 2020

HAL is a multi-disciplinary open access archive for the deposit and dissemination of scientific research documents, whether they are published or not. The documents may come from teaching and research institutions in France or abroad, or from public or private research centers.
L'archive ouverte pluridisciplinaire HAL, est destinée au dépôt et à la diffusion de documents scientifiques de niveau recherche, publiés ou non, émanant des établissements d'enseignement et de recherche français ou étrangers, des laboratoires publics ou privés. 


\title{
Voltammetric behaviour of Cationic Redox Probes at Mesoporous Silica Film Electrodes
}

\author{
Deomila Basnig, ${ }^{\text {a,b }}$ Neus Vilá, ${ }^{a}$ Grégoire Herzog, ${ }^{a}$ Alain Walcarius ${ }^{\mathrm{a}^{*}}$ \\ ${ }^{a}$ Laboratoire de Chimie Physique et Microbiologie pour les Matériaux et l'Environnement (LCPME), \\ UMR 7564, Université de Lorraine - CNRS, 405 Rue de Vandoeuvre, 54600 Villers-lès-Nancy, France \\ ${ }^{\mathrm{b}}$ Department of Natural Science, Caraga State University, Ampayon, Butuan City 8600, Philippines \\ *Corresponding author: alain.walcarius@univ-lorraine.fr
}

\begin{abstract}
The effect of vertically aligned silica nanochannels on the electrochemical response of various cationic redox probes has been investigated. To this end, an oriented mesoporous silica thin film has been generated by electro-assisted self-assembly onto a fluoride-doped tin oxide (FTO) electrode, which was then used to characterize the voltammetric behaviour of redox cations of different nature, size and charge. Methylene Blue $\left(\mathrm{MB}^{+}\right)$, paraquat $\left(\mathrm{PQ}^{2+}\right)$, diquat $\left(\mathrm{DQ}^{2+}\right)$, ruthenium trisbipyridine $\left(\mathrm{Ru}(\mathrm{bpy})_{3}{ }^{2+}\right)$ and ruthenium hexamine $\left(\mathrm{Ru}\left(\mathrm{NH}_{3}\right)_{6}{ }^{3+}\right)$ were selected for that purpose. Multisweep cyclic voltammetry experiments showed significant accumulation of these cations thanks to favourable electrostatic interactions with the negatively-charge silica surface, but the enhancement of the votammetric signals compared to the bare FTO electrode was strongly dependent on the probe type, according the following trend: $\mathrm{MB}^{+}>\mathrm{PQ}^{2+}>\mathrm{DQ}^{2+}$ $>\mathrm{Ru}($ bpy $) 3^{2+}>\mathrm{Ru}\left(\mathrm{NH}_{3}\right){ }_{6}{ }^{3+}$. The accumulation processes were very fast owing to the vertical orientation of the mesopore channels ensuring fast diffusion from the solution to the electrode surface. Operating at various potential scan rates and different probe concentrations enabled to quantify the relative ratio between surface-confined and diffusion-controlled processes, the adsorption phenomena being clearly more prominent in diluted media and also accentuated at high potential scan rates. The mesoporous silica film electrodes exhibited higher sensitivities at lower concentrations, which can give benefits for sensor applications at trace levels.
\end{abstract}

\section{Keywords}

Mesoporous silica film; modified electrode; redox cations; permeability; diffusion; accumulation. 


\section{Introduction}

The transport of ions and molecules in nanochannels and through nanopores has been extensively studied [1-6], notably because nanoporous membranes offer attractive features for applications in separation [7-12], sensors [13-15], catalysis [16,17], or energy storage [17]. Porous membranes made of nanochannels and nanopores are mostly prepared in the form of materials such as anodic aluminum oxide (AAO) [18-20], carbon nanotube (CNT) assemblies [21], polyethylene terephthalate (PET) nanochannels [22], self-organized nanotubes [23], zeolite nanoporous membranes [24-26], or boron nitride nanotube [27]. The nanochannels prepared from such materials are usually characterized by pore diameters above $10 \mathrm{~nm}$, which is basically useful for confinement of large molecules and species such as metal, metal oxide, polymers, and ionic liquids [5]. These are often subject to wettability issues, their mechanical and chemical stability needs to be improved, their pore size and density cannot always be accurately controlled, and vertical alignment of nanochannels may need complex processing [28]. Vertically-aligned nanoporous silica membranes made of a high density of hexagonallypacked mesopore channels with small and monodisperse diameters (in the $\sim 2-3 \mathrm{~nm}$ range) [18,29-31] can offer advantageous features, notably for the confinement and transport of small molecules and ions.

A versatile and fast way of preparing vertically-ordered silica nanochannels onto electrode surfaces is the use of the electrochemically assisted self-assembly (EASA) method, as developed in our group some time ago [29,30]. This method is likely to generate uniform thin films (with thicknesses ranging typically between 50 and $150 \mathrm{~nm}$ [30], or even more in multilayer configurations [31]) with pore sizes adjustable between 2 and $3 \mathrm{~nm}$ [32], and the mesochannels can be further functionalized with a variety of organic moieties [33-35]. Other synthetic approaches include the Stöber-solution growth [36], magnetically-induced orientation [37], epitaxial growth [38], or via an oil-induced co-assembly process [39]. Such oriented nanochannel membranes are very promising for applications, especially in the fields of electrochemical sensing and separation at molecular level [40-43]. Their performance can be affected by various factors such as the mesopore size [32,44], the mesochannel length/thickness $[45,46]$, the solution $\mathrm{pH}$ and/or ionic strength $[47,48]$ and the surface charge of the pores $[43,49]$. They are also attractive hosts for inclusion of redox mediator species or adsorption/confinement of other catalysts, for applications in electrocatalytic or electrochemiluminescence sensing, for instance [50-56]. 
Vertically ordered silica mesochannel films exhibit molecular sieving properties and permselective ion transport (Scheme 1). The size selectivity of mesoporous silica membranes has been demonstrated using molecular probes with dimensions greater than the pore diameter $[28,32,57]$. For example, on the basis of silica membranes with distinct pore sizes (i.e., 2.0 and $2.9 \mathrm{~nm}$ ), it has been shown that a ferrocenyl dendrimer (critical size of about $2.4 \mathrm{~nm}$ ) can only be detected at the underlying electrode surface by diffusion through the larger nanochannels $(2.9 \mathrm{~nm})$ while being totally excluded from the film made of narrower pores $(2.0 \mathrm{~nm})$ [32]. Cationic fluorophores of similar geometries but different sizes have been used to evidence possible permeation for the smaller ones (i.e., ruthenium trisbipyridine, $\mathrm{Ru}(\mathrm{bpy}) 3^{2+}$, and ruthenium trisphenanthroline, $\mathrm{Ru}(\text { phen })_{3}{ }^{2+}$, with molecular size of $1.3 \mathrm{~nm}$ ), whereas bigger species (ruthenium trisdiphenylphenanthroline, $\mathrm{Ru}(\mathrm{dpp}) 3^{2+}, 2.0 \mathrm{~nm}$ in diameter) were excluded from the mesoporous silica membrane [28]. The size exclusion of small proteins (such as hemoglobin) from silica mesochannels was demonstrated and applied as protective barrier against biofouling [57,58]. Note that similar molecular sieving effects have been also reported for non-silica mesoporous membranes (permeation of methylene blue, $\mathrm{MB}^{+}$(diameter, $1.4 \mathrm{~nm}$ ), and rejection of rhodamine $6 \mathrm{G}, \mathrm{R}_{6} \mathrm{G}^{+}$, (diameter, $1.8 \mathrm{~nm}$ ), at vertically aligned nanopores in a polymer membrane having a pore size of 1.2-1.4 nm) [9]. In addition, the vertically-ordered silica nanochannels are otherwise characterized by charge selectivity issues. At $\mathrm{pH}$ greater than 3 , the silica surface is expected to be negatively charged owing to its isoelectric point of 2-3 $[59,60]$. As a consequence, when working in usual media (at moderately acidic or neutral $\mathrm{pH}$ values), the mesoporous silica films on electrodes acted as a permselective membrane, enabling an easy transport of positively-charged redox probes (such as ruthenium hexamine, $\left.\mathrm{Ru}_{(\mathrm{NH}}\right)_{6}{ }^{3+}$, for instance) while rejecting the anionic ones (as ferricyanide, $\mathrm{Fe}(\mathrm{CN})_{6}{ }^{3-}$ ), resulting in large electrochemical signals for cations (sometimes larger than at bare electrode due to some accumulation) and low currents for anions (as a result of electrostatic repulsions preventing the negatively-charged redox probes to reach the underlying electrode surface) $[44,61]$. Such charge selectivity was similarly observed recently with polymer-based nanochannel membranes, exhibiting, e.g. selective permeation of methylene blue, $\mathrm{MB}^{+}$, over methyl orange, $\mathrm{MO}^{-}$[9]. By contrast, small neutral molecules (such as ferrocene dimethanol or catechol) can freely diffuse through the mesoporous silica membranes and be detected onto the underlying electrode surface [47,62], yet with some influence of the mesopore diameter on the transport rates [63]. Attempts to modulate the permselective behaviour, especially to promote the detection of anionic redox species, have been reported in the literature, by means of turning the internal surface of nanochannels from negative to positive (by working in highly acidic media 
[48], or by grafting positively-charged ammonium groups to the silica surface $[61,64])$, by operating in very high supporting electrolyte concentrations [65], or by using neutral redox mediators acting as electron shuttles for carrying charges from through the mesoporous film [62]. The transport of charged species through such regular and narrow channels bearing charges onto their internal surface was found to be highly depending on the ionic strength (defining the thickness of the electrical double layer at the silica surface as an interplay with the mesopore size) $[47,48,61]$. Hydrophobic effects on mass transport processes have been also reported [66,67]. To date, however, no extensive studies on the factors affecting the accumulation and electrochemical response of redox cations at oriented mesoporous silica film electrode, depending on their characteristics (nature, charge, size), have been made.

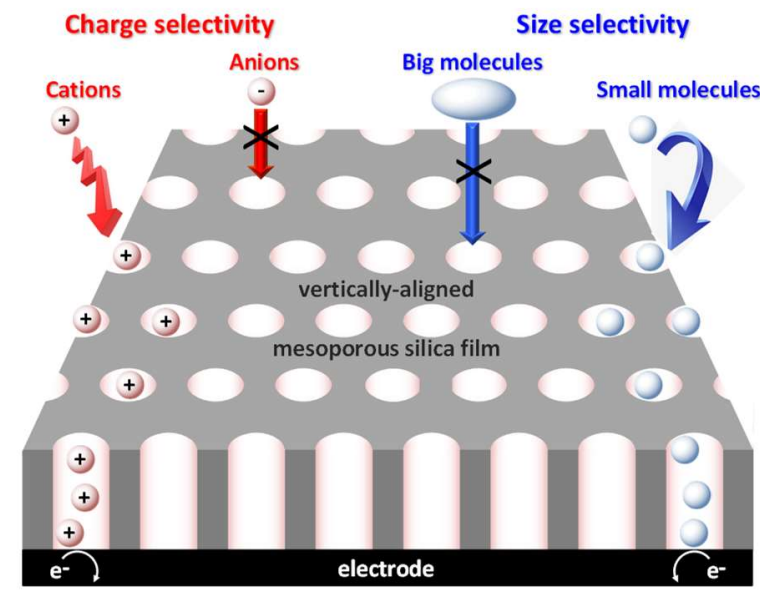

Scheme 1: Illustration of charge and size selectivity at vertically aligned mesoporous silica film. The film thickness is generally $80-150 \mathrm{~nm}$ with 2-3 $\mathrm{nm}$ pore diameters.

Here, we have thus investigated the voltammetric behaviour of various positivelycharged redox species at an fluorine-doped tin oxide (FTO) electrode covered with an oriented mesoporous silica film generated by EASA. The probes have been chosen for their different nature (organic or inorganic), charge (mono-, di- or tri-cationic) and size (yet, all of them being smaller than the nanochannels diameter to avoid any size-exclusion effects). These include paraquat $\left(\mathrm{PQ}^{2+}\right.$, also called methylviologen $)$, diquat $\left(\mathrm{DQ}^{2+}\right)$, methylene blue $\left(\mathrm{MB}^{+}\right)$, ruthenium hexamine $\left(\mathrm{Ru}\left(\mathrm{NH}_{3}\right)_{6}{ }^{3+}\right)$ and ruthenium tris-bipyridine $\left(\mathrm{Ru}(\mathrm{bpy})_{3}{ }^{2+}\right)$. Their confinement in the silica nanochannels was mainly monitored by multisweep cyclic voltammetry, in comparison to the bare FTO electrode and at various probe concentrations, as well as after open-circuit 
accumulation and subsequent voltammetric analysis. The extent of accumulation was strongly dependent on the probe type, as discussed in this paper.

\section{Experimental section}

\subsection{Chemicals and Reagents}

Tetraethoxysilane (TEOS, 98\%, Alfa Aesar), cetyltrimethyammonium bromide ( $\mathrm{C}_{16} \mathrm{TAB}, 99 \%$, Acros), ethanol (95-96\%, Merck), and $\mathrm{HCl}$ (1.0 M, Sigma-Aldrich) were used for the electrochemically assisted self-assembly (EASA) of mesoporous silica films on fluorinedoped-tin oxide (FTO) plates (surface resistivity 10-14 $\Omega \mathrm{cm}^{-2}$, Delta Technologies). Potassium ferrocyanide, $\left(\mathrm{K}_{4} \mathrm{Fe}(\mathrm{CN})_{6}, 99.5 \%\right.$, Fluka), Ferrocenemethanol $\left(\mathrm{C}_{11} \mathrm{H}_{12} \mathrm{FeO}, 97 \%\right.$, Alfa Aesar) and hexaammineruthenium(III) chloride $\left(\mathrm{Ru}\left(\mathrm{NH}_{3}\right)_{6} \mathrm{Cl}_{3}, 98 \%\right.$, Sigma-Aldrich), Paraquat (1-1'-dimethyl-4-4'-bipyridinium dichloride, 98\%, Sigma-Aldrich), Diquat $\left(\mathrm{C}_{12} \mathrm{H}_{12} \mathrm{Br}_{2} \mathrm{~N}_{2}, \mathrm{H}_{2} \mathrm{O}, 99 \%\right.$, Riedel-de Haën), Methylene Blue $\left(\mathrm{C}_{16} \mathrm{H}_{18} \mathrm{ClN}_{3} \mathrm{~S} \times \mathrm{x}_{2} \mathrm{O}\right.$, Fluka), Ruthenium Trisbipyridine or Tris(2,2'-bipyridyl)dichlororuthenium(II) hexahydrate $\left(\mathrm{C}_{30} \mathrm{H}_{24} \mathrm{Cl}_{2} \mathrm{~N}_{6} \mathrm{Ru} \cdot \mathrm{H}_{2} \mathrm{O}, 98 \%\right.$, Acros) were used as redox probes in the cyclic voltammetry experiments. Sodium nitrate $\left(\mathrm{NaNO}_{3}, 99 \%\right.$, Fluka) was used as the supporting electrolyte.

\subsection{Electrochemical Measurements}

Cyclic voltammetry measurements were carried out using either an EMStat2 or a PalmSens potentiostat (PalmSens, Netherlands) in the absence of oxygen (achieved through $\mathrm{N}_{2}$ purging for $20 \mathrm{~min})$. A three- electrode system using an $\mathrm{Ag} / \mathrm{AgCl}(3 \mathrm{M} \mathrm{KCl})$ reference electrode (Metrohm) and a stainless steel rod as the counter electrode, and FTO plates as working electrode, modified with mesoporous silica thin films. The background electrolyte for the cyclic voltammetry experiments was at $70 \mathrm{mM} \mathrm{NaNO}_{3}$, as it was optimized in a previous study [47].

\subsection{Preparation of mesoporous silica thin films}

The oriented mesoporous silica thin films were deposited electrochemically into FTO electrodes according to a previously reported procedure [29]. A starting sol solution containing $100 \mathrm{mM}$ TEOS as the silica precursor, $32 \mathrm{mM}$ surfactant as template, and $\mathrm{NaNO}_{3}(0.1 \mathrm{M})$ as supporting electrolyte was prepared in a water: ethanol (1:1) solution adjusted to a $\mathrm{pH}$ of 3 using $0.1 \mathrm{M} \mathrm{HCl}$ solution. The solution was hydrolysed for $2.5 \mathrm{~h}$ and used for electrochemical deposition of silica by applying $-1.5 \mathrm{~V}$ for $25 \mathrm{~s}$ in FTO as a working electrode with a diameter of $0.8 \mathrm{~cm}$, the reference electrode was a silver wire, and a stainless steel plate as a counter 
electrode. The modified FTO electrode surface was rinsed immediately with water and dried overnight at $130^{\circ} \mathrm{C}$. The template was removed by solvent extraction, by immersion of the film in $0.1 \mathrm{M} \mathrm{HCl} /$ Ethanol solution for a minimum of $15 \mathrm{~min}$. Mesoporous silica films with and without surfactants were further characterized by GISAXS, TEM and electrochemical techniques. The full characterization is described in the supplementary information (Figure S1 and associated text).

Grazing-incidence small-angle scaterring (GISAXS) experiments were carried out on "SAXSess $\mathrm{mc}^{2}$ " intrument (Anton Paar) with GISAXS equiped "VarioStageXY". This instrument is attached to a ID 3003 laboratory X-ray generator (General Electric) equiped with a sealed X-ray tube (PANalytical, $\lambda \mathrm{Cu}, \mathrm{K} \alpha=0.1542 \mathrm{~nm}$ ) operating at $40 \mathrm{kV}$ and $50 \mathrm{~mA}$. Scattering of X-ray beam was registered by a CCD detector (Princeton Instruments, $2084 \times$ 2084 pixels array with $24 \times 24 \mu^{2}$ pixel size) at $299 \mathrm{~mm}$ distance from the sample. Using Winspec32 software (Princeton Instruments), the 2D image was integrated into onedimensional scattering intensities I(q) as a function of the magnitude of the scattering vector qz $=(4 \pi / \lambda) \sin (\theta), \theta$ is the specular reflectance angle. The level of mesostructural order was evaluated by transmission electron microscopy (TEM) using a PhilipsCM20 microscope at an acceleration voltage of $200 \mathrm{kV}$. The samples were prepared by removing some pieces of the films, which were supported on a carbon-coated copper grid.

\section{Results and Discussion}

\subsection{Accumulation of different cationic redox probes inside the mesochannels}

The effect of oriented mesoporous silica thin film on FTO electrode was investigated by cyclic voltammetry in order to point out possible differences in the accumulation of cationic redox probes with different positive charges (ranging from +1 to +3 ), sizes, and molecular structure. The redox probes used in this study were paraquat $\left(\mathrm{PQ}^{2+}\right)$, diquat $\left(\mathrm{DQ}^{2+}\right)$, methylene blue $\left(\mathrm{MB}^{+}\right)$, ruthenium trisbipyridine $\left(\mathrm{Ru}(\mathrm{bpy})_{3}{ }^{2+}\right)$, and ruthenium hexamine $\left(\mathrm{Ru}\left(\mathrm{NH}_{3}\right)_{6}{ }^{3+}\right)$. Cyclic voltammetry of the various probes was run 50 times to allow reaching steady-state current values (Figure S2). Figure 1 showed the $50^{\text {th }}$ cyclic voltammograms obtained at both bare (dashed curves) and mesoporous silica thin film electrodes (solid lines) for the five redox probes. Since the silica surface has an isoelectric point of $2[44,68-70]$, silanolate groups are present on the silica surfaces in $\mathrm{pH}$ conditions used here (unbuffered solutions with $\mathrm{pH}$ values around 6.5), leading to favourable electrostatic interactions with the cationic redox probes. The 
absence of an adsorption prepeak for all redox probes (Figure S2) suggests a weak type of adsorption on mesoporous silica [71], with similar formal potentials for the adsorbed and the non-adsorbed redox couples [72]. For all redox probes investigated, the electrochemical signals were enhanced with mesoporous silica compared to the bare electrode (Figure 1), suggesting that all cationic probes were accumulated in the mesochannels of the silica films. However, the extent of the accumulation varied significantly from one probe to another. The highest current response was observed for $\mathrm{MB}^{+}$with a 13 -fold increase of the peak current after accumulation whereas the signal for $\mathrm{Ru}\left(\mathrm{NH}_{3}\right)_{6}{ }^{3+}$ was improved only by a factor 1.4. The order for the enhanced electrochemical signal of the cationic redox probes is the following: $\mathrm{MB}^{+}>\mathrm{PQ}^{2+}>$ $\mathrm{DQ}^{2+}, \mathrm{Ru}(\mathrm{bpy})_{3}{ }^{2+}>\mathrm{Ru}\left(\mathrm{NH}_{3}\right)_{6}{ }^{3+}$. It seems therefore that multicationic species are less efficiently accumulated than the monocation, which can be due to the fact that they required more counteranions from the electrolyte to maintain charge balance [47] (anion transport is restricted in such silica channels [48]). At same charge, the size of the probe might have some effect (i.e., more effective accumulation of $\mathrm{PQ}^{2+}$ having a kinetic diameter of $0.58 \mathrm{~nm}[73]$ than $\mathrm{DQ}^{2+}$ with kinetic diameter of about $0.7 \mathrm{~nm}$ [74]) but this is expected to be quite limited if considering that the bulkier cation $\left(\mathrm{Ru}(\mathrm{bpy}){ }_{3}{ }^{2+}\right.$, characterized by a size of $\left.1.2-1.3 \mathrm{~nm}[75]\right)$ led to enhancement values close to that of $\mathrm{DQ}^{2+}$ (compare green and orange curves in Fig. 1).

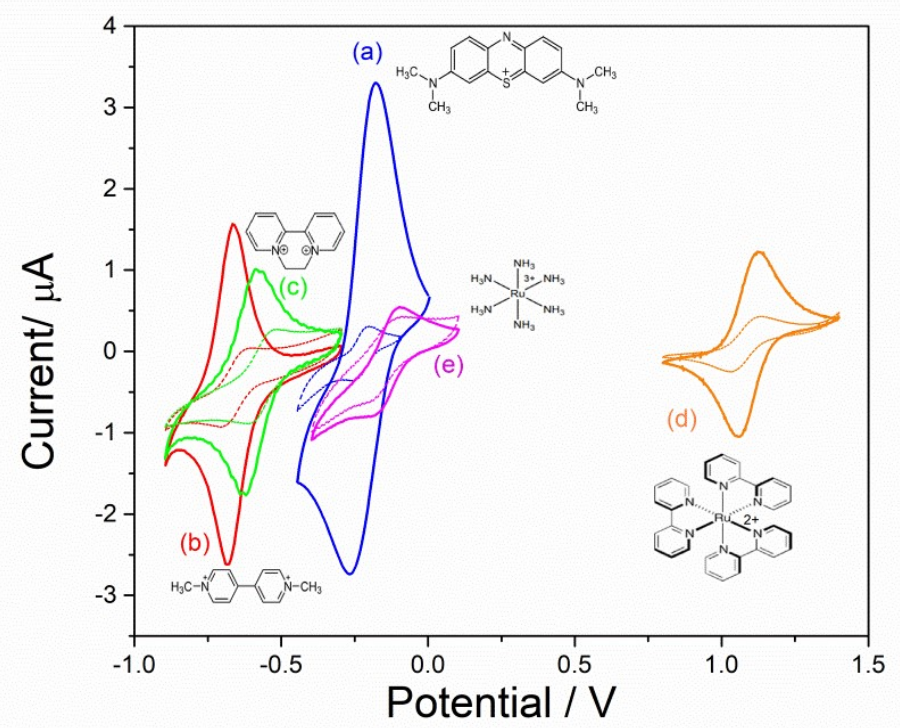

Figure 1: Cyclic voltammograms of various redox probes recorded at bare FTO (dashed line) and at mesoporous silica film modified FTO (straight line) electrodes: (a) $\mathrm{MB}^{+}$; (b) $\mathrm{PQ}^{2+}$; (c) $\mathrm{DQ}^{2+}$; (d) $\mathrm{Ru}(\mathrm{bpy})_{3}{ }^{2+}$; (e) $\mathrm{Ru}\left(\mathrm{NH}_{3}\right)_{6}{ }^{3+}$; the curves correspond to the $50^{\text {th }}$ cycle obtained after multiple potential scanning at $20 \mathrm{mV} \mathrm{s}^{-1}$; The concentration for all probes was $20 \mu \mathrm{M}$, in a supporting electrolyte solution made of $70 \mathrm{mM} \mathrm{NaNO}_{3}$. 
Figure 2 showed the evolution of the absolute peak current value of the forward scan as a function of the number of cycles for both the silica film electrode (part A) and the bare FTO electrode (part B). Peak currents at the bare electrode were constant (independent on the number of cycles) for the five redox probes, and much lower than those recorded for the film electrode, confirming that the accumulation behavior is due to the presence of mesoporous silica thin films. For $\mathrm{MB}^{+}, \mathrm{PQ}^{2+}, \mathrm{DQ}^{2+}$ and $\mathrm{Ru}(\mathrm{bpy})_{3}{ }^{2+}$, the forward peak current rapidly increased in the first few cycles (10-20 cycles), before reaching a plateau. Even, the first cycle for each probe led to current values much larger than at bare FTO, with magnitudes of more than $50 \%$ of the maximal steady-state values, indicating quite fast accumulation processes (thanks to the vertical channels). The increase in current in the initial stage is due to transport-limited by diffusion accompanied by rapid adsorption onto the silica substrate [76-78]. Once the full coverage of the silica surface is attained, redox probes will no longer adsorb as shown by the plateau in the curve. For $\mathrm{Ru}\left(\mathrm{NH}_{3}\right)_{6}{ }^{3+}$, the peak current remained more or less constant throughout the series of cycles, suggesting that its adsorption is limited, despite a charge of +3 . Actually, a main difference between this probe and the four above ones is the absence of aromatic rings; accordingly, it seems that the presence of aromatic moieties in the cationic probes contributed to improve their binding to the silica surface, which might be due to non-covalent forces between electron deficient aromatic systems of the redox cations and silanolate anions (i.e., $\pi$-anion interactions [79]), in addition to the more classical electrostatic interactions.
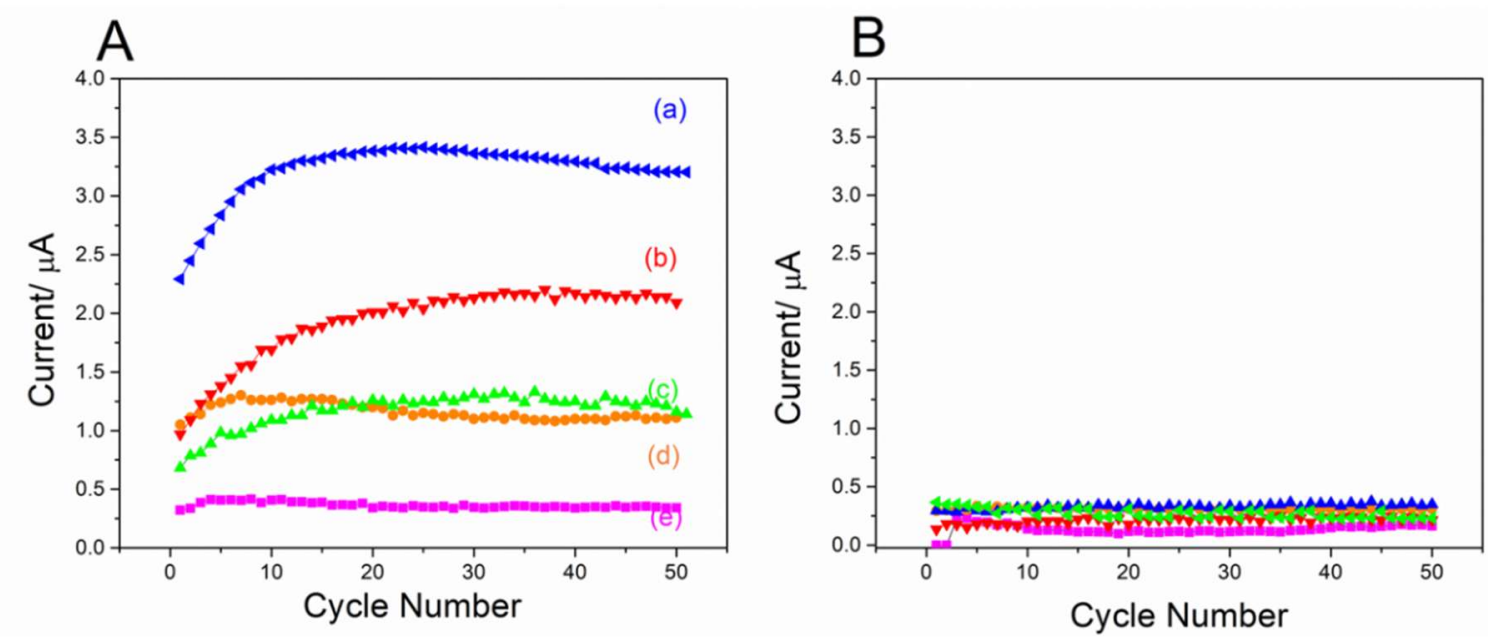

Figure 2: Forward peak current as a function of the number of cycles for the various cationic redox probes at (A) a mesoporous silica film and (B) a bare FTO electrode for $\mathrm{MB}^{+}$(a, blue); $\mathrm{PQ}^{2+}$ (b, red); $\mathrm{DQ}^{2+}$ (c, green); $\mathrm{Ru}(\mathrm{bpy}) 3^{2+}$ (d, orange); and $\mathrm{Ru}\left(\mathrm{NH}_{3}\right)_{6}{ }^{3+}$ (e, magenta). All the experimental conditions were the same as Figure S2. 


\subsection{Thin-layer versus semi-infinite diffusion}

In order to investigate further the behabiour of various redox probes in mesoporous silica thin films, cyclic voltammetry studies were conducted at two different concentrations (20 and $1000 \mu \mathrm{M})$ after accumulation at open-circuit potential for $30 \mathrm{~min}$. Control experiments showed that the peak current increased with accumulation time, before reaching a plateau (Figure S3). Figure 3 shows the cyclic voltammograms recorded for $\mathrm{DQ}^{2+}$ at the two concentrations for scan rates varying from 10 to $100 \mathrm{mV} \mathrm{s}^{-1}$. At the lowest concentration (Fig. $3 \mathrm{~A}$ ), the peak-to-peak separation was approximatively $0.03 \mathrm{~V}$, indicating an electrochemical response mainly controlled by the redox molecules adsorbed on the silica and corresponding to thin layer diffusion. When the concentration raised to $1000 \mu \mathrm{M}$ (Fig. 3B), the peak-to-peak separation increased to $0.09 \mathrm{~V}$ (at $10 \mathrm{mV} \mathrm{s}^{-1}$ ) suggesting a semi-infinite diffusion-controlled reaction. These observations were further supported by the scan rate studies. When the redox probe concentration was $20 \mu \mathrm{M}$, the peak current varied linealry with the scan rate (Fig. 3A, inset), confirming that the electrochemical response is dominated by adsorbed species. On the other hand, diffusion of redox probes is dominating the electrochemical response at the highest concentration as established by the linear variation of the peak current with the square root of the scan rate (Fig. 3B, inset). Similar behaviour was observed for the other redox probes (Figure S4).

A

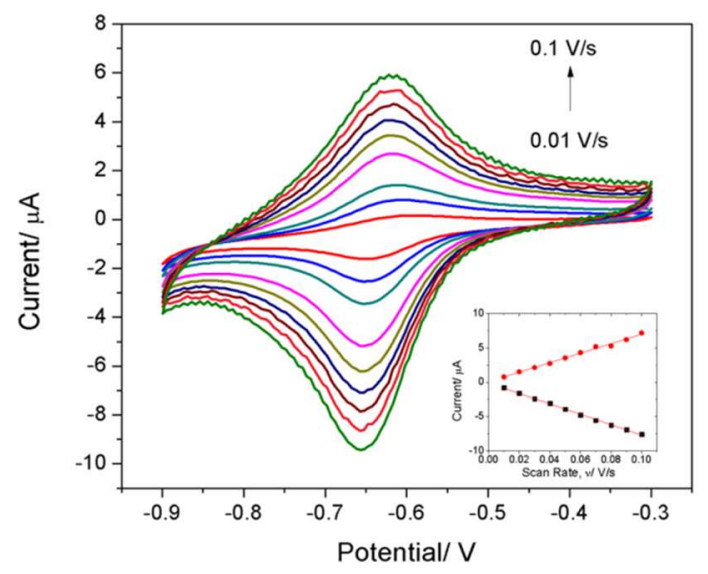

B

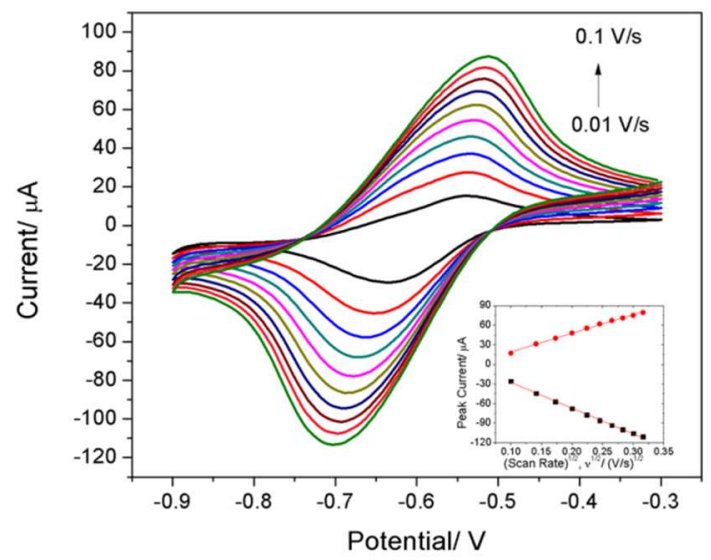

Figure 3: Cyclic voltammograms of (A) $20 \mu \mathrm{M}$ and (B) $1000 \mu \mathrm{M} \mathrm{DQ}^{2+}$ on mesoporous silica film with scan rates ranging from $10-100 \mathrm{mV} \mathrm{s}^{-1}$. Insets show the peak current as a function of (A) scan rate, $v$, and (B) square root of scan rate, $v^{1 / 2}$. 
Logarithmic plots of current vs scan rates are shown in Figure 4 for the different redox probes. A slope of 1 indicates that the electrochemical response is confined to a thin-layer behaviour whereas a slope of 0.5 is due to a semi-infinite diffusion process according to Randles-Sevčik equation [80]. At the lower concentration of $\mathrm{DQ}^{2+}$ and $\mathrm{PQ}^{2+}$, adsorbed species are dominating the electrochemical response as indicated by the slope of nearly 1 recorded. However, for the same concentration of $\mathrm{Ru}\left(\mathrm{NH}_{3}\right)_{6}{ }^{3+}$ and $\mathrm{Ru}(\mathrm{bpy})_{3}{ }^{2+}$, a mixed behaviour, with both diffusion and thin-layer processes, was observed (slopes were measured at 0.85 and 0.80 for $\mathrm{Ru}\left(\mathrm{NH}_{3}\right)_{6}{ }^{3+}$ and $\mathrm{Ru}(\mathrm{bpy}) 3^{2+}$, respectively). These slope values lower than unity (Figure 4A), supported that geometry of the cationic probes may play a role in the electrochemical behaviour observed in such confined channels. In the case of $\mathrm{Ru}(\mathrm{bpy}) 3^{2+}$, this is further demonstrated by the deviation from the linear behaviour observed when the scan rate increased. This differences of behaviour could be attributed to either an effect of the pseudo-diffusion of electrons or to the limitation of counter-ions diffusion in the mesochannels. When probe concentrations were increased, the slope values approached closer to 0.5 , which indicated the transition from thin layer behaviour to semi-infinite diffusion. At these higher concentrations, there was no significant behaviour between the different redox probes (Figure 4B).
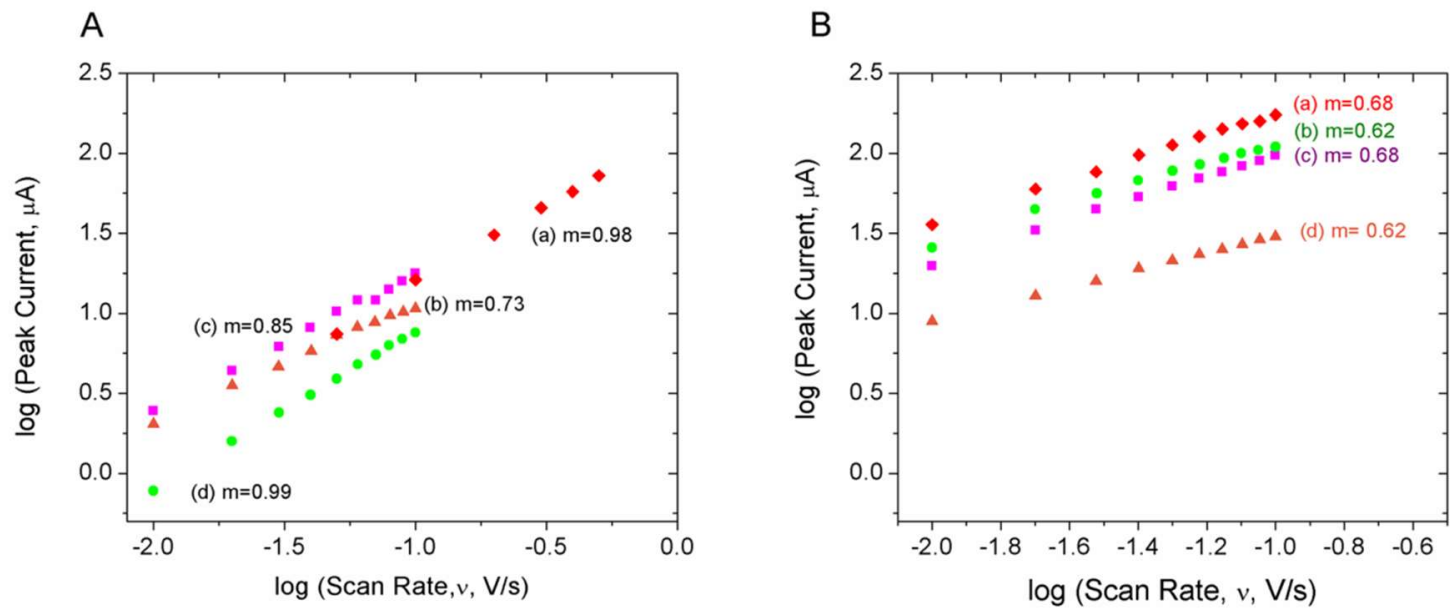

Figure 4: Logarithmic plots of peak current vs scan rate at low concentration for $\mathrm{PQ}^{2+}$ (a), $\mathrm{DQ}^{2+}$ (b), $\mathrm{Ru}\left(\mathrm{NH}_{3}\right)_{6}{ }^{3+}$ (c), and $\mathrm{Ru}(\mathrm{bpy})_{3}{ }^{2+}$ (d) at (A) low $(20 \mu \mathrm{M})$ and (B) high concentration (1000 $\mu \mathrm{M}$ for $\mathrm{PQ}^{2+}, \mathrm{DQ}^{2+}$ and $\mathrm{Ru}\left(\mathrm{NH}_{3}\right)_{6}{ }^{3+}$, and $500 \mu \mathrm{M}$ for $\left.\mathrm{Ru}(\text { bpy })_{3}{ }^{2+}\right)$. All parameters are the same as for Figure 3.

In the case of mixed behaviour, both diffusion-controlled and thin layer-confined reactions contributed to the recorded current, which was assessed using the following equation [81]:

$$
i=k_{1} v+k_{2} v^{1 / 2}
$$


In equation (1), $i$ is the current measured at a given potential, $v$ was the scan rate and $k_{l}$ and $k_{2}$ were empirical parameters representing the thin layer and the diffusion contributions, respectively. Normalising equation (1) led to equation 2:

$$
\frac{i}{v^{1 / 2}}=k_{1} v^{1 / 2}+k_{2}
$$

The values for the parameters $k_{1}$ and $k_{2}$ were extracted from the plots of normalized current values vs the square root of potential scan rate. The thin-layer confined and semi-infinite diffusion contributions to the current were plotted for different scan rates and concentrations (Figure 5). At the low concentration values, the electrochemical response is dominated by the reaction confined in the thin layer and its contribution increased slightly with the scan rate (Figure 5A). When the redox probe concentration is higher, the contribution of semi- infinite diffusion became dominant (Figure 5B). However, a complete comparison on the effect of the thin-layer diffusion the different redox probes is difficult, because of pseudo-diffusion of electrons [72] and of the counter ion diffusion through the film $[47,82]$. Nevertheless, the dominating thin-layer behaviour for the lower concentration (i.e. $20 \mu \mathrm{M}$ ), was observed for the redox probes investigated (as shown in Figure S5).

A

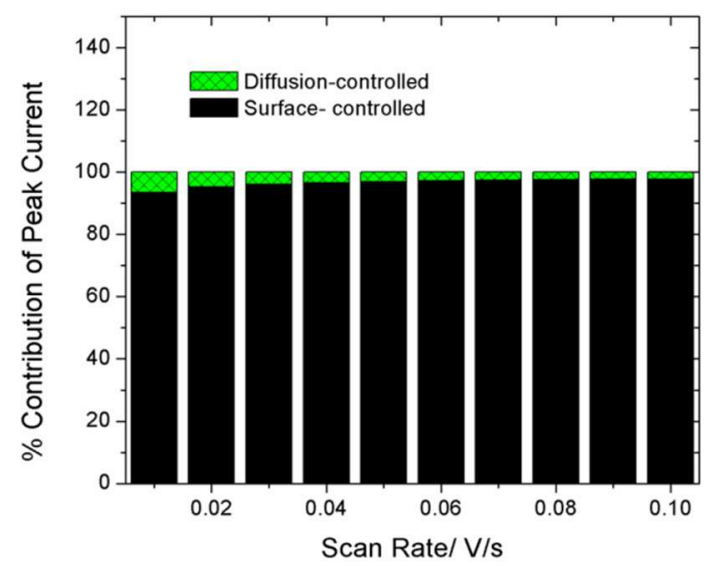

B

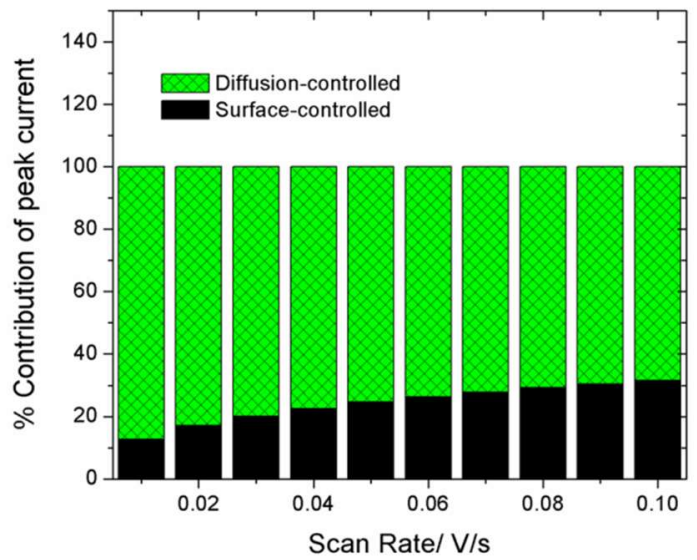

Figure 5: Contribution of thin-layer and semi-infinite diffusions to the current at mesoporous silica thin film electrodes for $\mathrm{DQ}^{2+}$ at (A) 20 and (B) $1000 \mu \mathrm{M}$. Scan rates were ranging from 0.01 to $0.1 \mathrm{~V} \mathrm{~s}^{-1}$. Supporting electrolyte was $70 \mathrm{mM} \mathrm{NaNO}_{3}$. Similar graphs for the other redox probes are shown in supplementary information. 


\subsection{Effect of redox probe concentration on its accumulation in the mesochannels}

The concentration of redox probes was varied between $10 \mu \mathrm{M}$ and $8 \mathrm{mM}$ and the forward peak current of cyclic voltammograms obtained at both bare and mesoporous silica film electrodes was plotted as a function of concentration (Figure 6). A linear response was observed for low concentrations of $\mathrm{PQ}^{2+}\left(10-200 \mu \mathrm{M}, R^{2}=0.999\right)$, but exhibited two other different linear ranges at higher concentrations: $300-1000 \mu \mathrm{M}\left(R^{2}=0.985\right)$ and $2000-8000 \mu \mathrm{M}\left(R^{2}=\right.$ 0.996). As the concentration increased, the sensitivity of the modified electrode towards the redox probe decreased as shown by the results in Table 1; unlike the sensitivity at the bare electrode, which remained relatively constant throughout the $10-8000 \mu \mathrm{M}$ concentration range. At the lower concentration range $(10-200 \mu \mathrm{M})$, the sensitivity for $\mathrm{PQ}^{2+}$ at the mesoporous silica film electrode was three times higher than at the bare electrode, while the ratio of sensitivity of modified / bare electrode dropped to 1.8-fold for the $300-1000 \mu \mathrm{M}$. This decrease of sensitivity with the concentration observed at the mesoporous silica electrode is consistent with the fall of the contribution of thin-layer diffusion and the increasing contribution of semiinfinite diffusion. At the highest concentration $(8000 \mu \mathrm{M})$, the signal recorded at the modified electrode was even lower than at bare FTO, which is ascribed to restricted mass transport through mesochannels containing such large amounts of $\mathrm{PQ}^{2+}$. For the lowest concentrations, improved sensitivities for the mesoporous silica film electrodes were also observed for $\mathrm{Ru}\left(\mathrm{NH}_{3}\right)_{6}{ }^{3+}$ (1.5-fold improvement) and for $\mathrm{Ru}(\mathrm{bpy})_{3}{ }^{2+}$ (3.2-fold improvement).

A

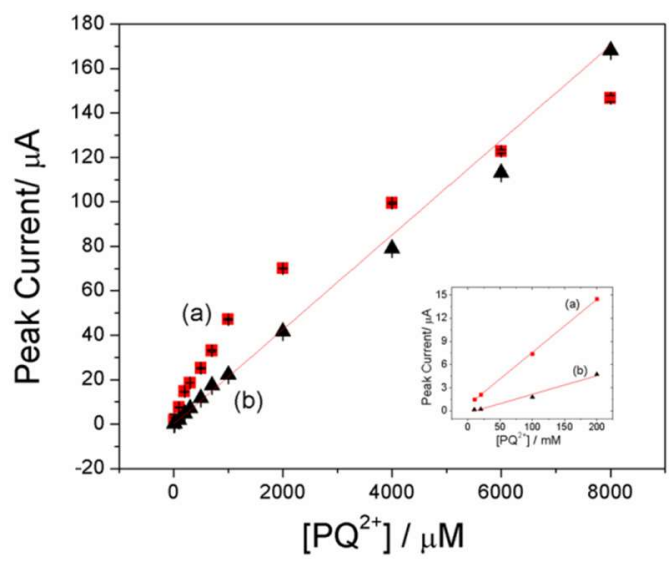

B

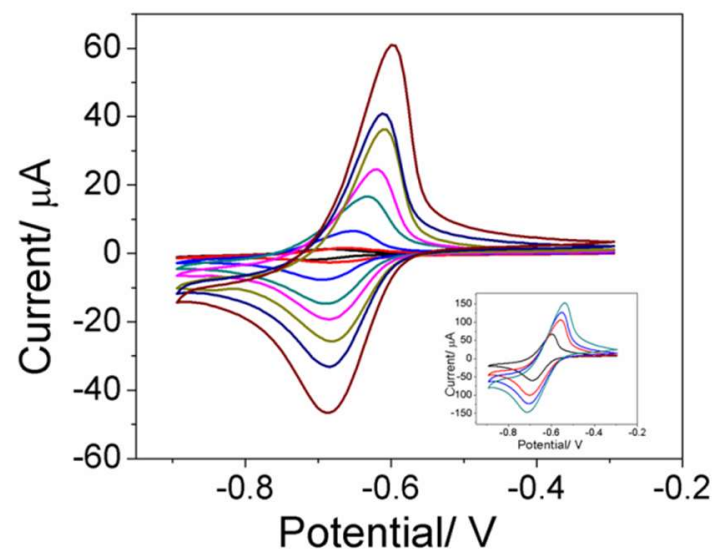

Figure 6: (A) Cyclic voltammograms for $10-1000 \mu \mathrm{M} \mathrm{PQ}^{2+}$ at a mesoporous silica film electrode $\left(50^{\text {th }}\right.$ cycles $)$; supporting electrolyte was $70 \mathrm{mM} \mathrm{NaNO}_{3} ; v=20 \mathrm{mV} \mathrm{s}^{-1}$. Inset shows cylic voltammograms in the $2000-8000 \mu \mathrm{M}$ concentration range. (B) Calibration curves of 
$\mathrm{PQ}^{2+}$ at a mesoporous silica film electrode (a, red squares) and at bare FTO electrode (b, black triangles).

Table 1: Sensitivities for $\mathrm{PQ}^{2+}, \mathrm{Ru}(\mathrm{bpy}) 3^{2+}$, and $\mathrm{Ru}\left(\mathrm{NH}_{3}\right) 6^{3+}$ at mesoporous silica films and bare FTO electrodes

\begin{tabular}{|c|c|c|c|c|}
\hline Electrode & Probe & $\begin{array}{c}\text { Dynamic range / } \\
\mu \mathrm{M}\end{array}$ & $\begin{array}{c}\text { Sensitivity } \\
/ \mathrm{A} \mathrm{M}^{-1} \\
\mathrm{~cm}^{-2}\end{array}$ & $R^{2}$ \\
\hline \multirow{5}{*}{ Mesoporous silica film } & \multirow{3}{*}{$\mathrm{PQ}^{2+}$} & $10-200$ & 0.274 & 0.999 \\
\hline & & $300-1000$ & 0.162 & 0.986 \\
\hline & & $2000-8000$ & 0.052 & 0.996 \\
\hline & $\mathrm{Ru}(\mathrm{bpy}) 3^{2+}$ & $2-20$ & 0.192 & 0.991 \\
\hline & $\mathrm{Ru}\left(\mathrm{NH}_{3}\right)_{6}{ }^{3+}$ & $10-100$ & 0.095 & 0.999 \\
\hline \multirow{5}{*}{ Bare FTO electrode } & \multirow{3}{*}{$\mathrm{PQ}^{2+}$} & $10-200$ & 0.089 & 0.998 \\
\hline & & $300-1000$ & 0.092 & 0.997 \\
\hline & & $2000-8000$ & 0.080 & 0.998 \\
\hline & $\mathrm{Ru}(\mathrm{bpy})_{3}{ }^{2+}$ & $2-20$ & 0.065 & 0.977 \\
\hline & $\mathrm{Ru}\left(\mathrm{NH}_{3}\right)_{6}{ }^{3+}$ & $10-100$ & 0.060 & 0.998 \\
\hline
\end{tabular}

\section{Conclusions}

The aim of this study was to characterize the accumulation of cationic redox probes at electrodes modified with mesoporous silica films for the improvement of electrochemical sensors. The electrochemical signal of the cationic redox probes was enhanced in the following order: $\mathrm{MB}^{+}>\mathrm{PQ}^{2+}>\mathrm{DQ}^{2+}, \mathrm{Ru}(\text { bpy })_{3}{ }^{2+}>\mathrm{Ru}\left(\mathrm{NH}_{3}\right)_{6}{ }^{3+}$. Monocationic species are accumulated more efficiently, probably due to the necessity of more counter ions to diffuse with multicharged species to maintain the charge balance. Scan rate studies showed that thin-layer diffusion dominated at the lower concentration for all redox probes, even for $\mathrm{Ru}\left(\mathrm{NH}_{3}\right)_{6}{ }^{3+}$, which accumulation was rather limited compared to the other probes. As the redox probe concentration increased, semi-infinite diffusion contribution increased, cancelling out the benefit of accumulation. Mesoporous silica film electrodes exhibited higher sensitivities than bare electrodes at lower concentrations, which can give benefits for sensor applications at trace levels. 


\section{Acknowledgements}

This work was supported partly by the French PIA project "Lorraine Université d'Excellence" (Reference $\mathrm{N}^{\circ}$ ANR-15-IDEX-04-LUE). DB is grateful to CHED-PHILFRANCE and Campus France for sponsoring of her $\mathrm{PhD}$. M Lionel Richaudeau is thanked for his help with the GISAXS measurements.

\section{References}

[1] I. Zharov, A. Khabibullin, Surface-modified silica colloidal crystals: Nanoporous films and membranes with controlled ionic and molecular transport, Acc. Chem. Res. 47 (2014) 440-449. doi:10.1021/ar400157w.

[2] M. Tagliazucchi, I. Szleifer, Transport mechanisms in nanopores and nanochannels: Can we mimic nature?, Mater. Today. 18 (2015) 131-142. doi:10.1016/j.mattod.2014.10.020.

[3] F.H. Kriel, R. Sedev, C. Priest, Capillary Filling of Nanoscale Channels and Surface Structure, Isr. J. Chem. 54 (2014) 1519-1532. doi:10.1002/ijch.201400086.

[4] Z. Zhu, D. Wang, Y. Tian, L. Jiang, Ion/Molecule Transportation in Nanopores and Nanochannels: From Critical Principles to Diverse Functions, J. Am. Chem. Soc. 141 (2019) 8658-8669. doi:10.1021/jacs.9b00086.

[5] X. Zhang, H. Liu, L. Jiang, Wettability and Applications of Nanochannels, Adv. Mater. 31 (2019) 1-32. doi:10.1002/adma.201804508.

[6] H. Zhang, Y. Tian, L. Jiang, Fundamental studies and practical applications of bioinspired smart solid-state nanopores and nanochannels, Nano Today. 11 (2016) 61-81. doi:10.1016/j.nantod.2015.11.001.

[7] Q. Yang, X. Lin, B. Su, Molecular Filtration by Ultrathin and Highly Porous Silica Nanochannel Membranes: Permeability and Selectivity, Anal. Chem. 88 (2016) 1025210258. doi:10.1021/acs.analchem.6b02968.

[8] Y. Eygeris, E. V. White, Q. Wang, J.E. Carpenter, M. Grünwald, I. Zharov, Responsive Nanoporous Membranes with Size Selectivity and Charge Rejection from SelfAssembly of Polyelectrolyte "hairy" Nanoparticles, ACS Appl. Mater. Interfaces. 11 
(2019) 3407-3416. doi:10.1021/acsami.8b17483.

[9] X. Feng, K. Kawabata, G. Kaufman, M. Elimelech, C.O. Osuji, Highly Selective Vertically Aligned Nanopores in Sustainably Derived Polymer Membranes by Molecular Templating, ACS Nano. 11 (2017) 3911-3921. doi:10.1021/acsnano.7b00304.

[10] L.J. Small, D.R. Wheeler, E.D. Spoerke, Nanoporous membranes with electrochemically switchable, chemically stabilized ionic selectivity, Nanoscale. 7 (2015) 16909-16920. doi:10.1039/c5nr02939b.

[11] J. Yang, G.S. Lin, C.Y. Mou, K.L. Tung, Diatom-Mimicking Ultrahigh-Flux Mesoporous Silica Thin Membrane with Straight-Through Channels for Selective Protein and Nanoparticle Separations, Chem. Mater. 31 (2019) 1745-1751. doi:10.1021/acs.chemmater.8b05295.

[12] Y. Wang, J. Di, L. Wang, X. Li, N. Wang, B. Wang, et al., Infused-liquid-switchable porous nanofibrous membranes for multiphase liquid separation, Nat. Commun. 8 (2017) 1-7. doi:10.1038/s41467-017-00474-y.

[13] H. O. Lintang, K. Kinbara, T. Aida, Effect of acidic aqueous alcohol solution on template sol-gel synthesis of phosphorescent hexagonal mesoporous silica film nanocomposite, Malaysian J. Fundam. Appl. Sci. 7 (2014) 1-6. doi:10.11113/mjfas.v7n1.229.

[14] Y. Mo, T. Fei, NANOPOROUS MEMBRANE FOR BIOSENSING APPLICATIONS, Nano Life. 02 (2012) 1230003. doi:10.1142/S1793984411000323.

[15] F. Zhao, J. Wu, Y. Ying, Y. She, J. Wang, J. Ping, Carbon nanomaterial-enabled pesticide biosensors: Design strategy, biosensing mechanism, and practical application, TrAC - Trends Anal. Chem. 106 (2018) 62-83. doi:10.1016/j.trac.2018.06.017.

[16] J. Liu, S. Ma, Q. Wei, L. Jia, B. Yu, D. Wang, et al., Parallel array of nanochannels grafted with polymer-brushes-stabilized Au nanoparticles for flow-through catalysis, Nanoscale. 5 (2013) 11894-11901. doi:10.1039/c3nr03901c.

[17] Z.K. Yang, C.Z. Yuan, A.W. Xu, Confined Pyrolysis within a Nanochannel to Form a Highly Efficient Single Iron Site Catalyst for Zn-Air Batteries, ACS Energy Lett. 3 
(2018) 2383-2389. doi:10.1021/acsenergylett.8b01508.

[18] V. Urbanova, A. Walcarius, Vertically-aligned Mesoporous Silica Films, Z. Anorg. Allg. Chem. 640 (2014) 537-546. doi:10.1002/zaac.201300442.

[19] C.S. Law, S.Y. Lim, A.D. Abell, N.H. Voelcker, A. Santos, Nanoporous anodic alumina photonic crystals for optical chemo-and biosensing: Fundamentals, advances, and perspectives, Nanomaterials. 8 (2018). doi:10.3390/nano8100788.

[20] M.I. Vázquez, V. Romero, V. Vega, J. García, V.M. Prida, B. Hernando, et al., Morphological, chemical surface, and diffusive transport characterizations of a nanoporous alumina membrane, Nanomaterials. 5 (2015) 2192-2202. doi:10.3390/nano5042192.

[21] J.K. Holt, H.G. Park, Y. Wang, M. Stadermann, A.B. Artyukhin, C.P. Grigoropoulos, et al., Fast mass transport through sub-2-nanometer carbon nanotubes, Science (80-. ). 312 (2006) 1034-1037. doi:10.1126/science.1126298.

[22] M.R. Powell, L. Cleary, M. Davenport, K.J. Shea, Z.S. Siwy, Electric-field-induced wetting and dewetting in single hydrophobic nanopores, Nat. Nanotechnol. 6 (2011) 798-802. doi:10.1038/nnano.2011.189.

[23] T. Shimizu, H. Minamikawa, M. Kogiso, M. Aoyagi, N. Kameta, W. Ding, et al., Selforganized nanotube materials and their application in bioengineering, Polym. J. 46 (2014) 831-858. doi:10.1038/pj.2014.72.

[24] N. Rangnekar, N. Mittal, B. Elyassi, J. Caro, M. Tsapatsis, Zeolite membranes - a review and comparison with MOFs, Chem. Soc. Rev. 44 (2015) 7128-7154. doi:10.1039/c5cs00292c.

[25] H.J. Chang, T.Y. Chen, Z.P. Zhao, Z.J. Dai, Y.L. Chen, C.Y. Mou, et al., Ordered Mesoporous Zeolite Thin Films with Perpendicular Reticular Nanochannels of Wafer Size Area, Chem. Mater. 30 (2018) 8303-8313. doi:10.1021/acs.chemmater.8b03789.

[26] P. Woodtli, S. Giger, P. Müller, L. Sägesser, N. Zucchetto, M.J. Reber, et al., Indigo in the nanochannels of zeolite L: Towards a new type of colorant, Dye. Pigment. 149 (2018) 456-461. doi:10.1016/j.dyepig.2017.10.029.

[27] A. Siria, P. Poncharal, A.L. Biance, R. Fulcrand, X. Blase, S.T. Purcell, et al., Giant 
osmotic energy conversion measured in a single transmembrane boron nitride nanotube, Nature. 494 (2013) 455-458. doi:10.1038/nature11876.

[28] X. Lin, Q. Yang, L. Ding, B. Su, Ultrathin Silica Membranes with Highly Ordered and Perpendicular Nanochannels for Precise and Fast Molecular Separation, ACS Nano. 9 (2015) 11266-11277. doi:10.1021/acsnano.5b04887.

[29] A. Walcarius, E. Sibottier, M. Etienne, J. Ghanbaja, Electrochemically assisted selfassembly of mesoporous silica thin films., Nat. Mater. 6 (2007) 602-608. doi:10.1038/nmat1951.

[30] A. Goux, M. Etienne, E. Aubert, C. Lecomte, J. Ghanbaja, A. Walcarius, Oriented Mesoporous Silica Films Obtained by Electro-Assisted Self-Assembly (EASA), Chem. Mater. 21 (2009) 731-741. doi:10.1021/cm8029664.

[31] G. Giordano, N. Vilà, E. Aubert, J. Ghanbaja, A. Walcarius, Multi-layered, verticallyaligned and functionalized mesoporous silica films generated by sequential electrochemically assisted self-assembly, Electrochim. Acta. 237 (2017) 227-236. doi:10.1016/j.electacta.2017.03.220.

[32] N. Vilà, E. André, R. Ciganda, J. Ruiz, D. Astruc, A. Walcarius, Molecular Sieving with Vertically Aligned Mesoporous Silica Films and Electronic Wiring through Isolating Nanochannels, Chem. Mater. 28 (2016) 2511-2514. doi:10.1021/acs.chemmater.6b00716.

[33] N. Vilà, J. Ghanbaja, E. Aubert, A. Walcarius, Electrochemically Assisted Generation of Highly Ordered Azide-Functionalized Mesoporous Silica for Oriented Hybrid Films, Angew. Chemie Int. Ed. 53 (2014) 2945-2950. doi:10.1002/anie.201309447.

[34] M. Rafiee, B. Karimi, Y.A. Asl, H. Vali, Electrochemical fabrication of electroactive ordered mesoporous electrode, Analyst. 138 (2013) 1740-1744. doi:10.1039/c2an36325a.

[35] N. Vilà, J. Ghanbaja, A. Walcarius, Clickable Bifunctional and Vertically Aligned Mesoporous Silica Films, Adv. Mater. Interfaces. 3 (2016) 1500440. doi:10.1002/admi.201500440.

[36] Z. Teng, G. Zheng, Y. Dou, W. Li, C.-Y.Y. Mou, X. Zhang, et al., Highly Ordered 
Mesoporous Silica Films with Perpendicular Mesochannels by a Simple StöberSolution Growth Approach, Angew. Chem. Int. Ed. 51 (2012) 2173-2177. doi:10.1002/anie.201108748.

[37] Y. Yamauchi, M. Sawada, M. Komatsu, A. Sugiyama, T. Osaka, N. Hirota, et al., Magnetically induced orientation of mesochannels in mesoporous silica films at 30 Tesla, Chem. Asian J. 2 (2007) 1505-1512. doi:10.1002/asia.200700244.

[38] E.K. Richman, T. Brezesinski, S.H. Tolbert, Vertically oriented hexagonal mesoporous films formed through nanometre-scale epitaxy, Nat. Mater. 7 (2008) 712-717. doi:10.1038/nmat2257.

[39] K.C. Kao, C.H. Lin, T.Y. Chen, Y.H. Liu, C.Y. Mou, C.T. Y, et al., A General Method for Growing Large Area Mesoporous Silica Thin Films on Flat Substrates with Perpendicular Nanochannels, J. Am. Chem. Soc. 137 (2015) 3779-3782. doi:10.1021/jacs.5b01180.

[40] A. Walcarius, Mesoporous Materials-Based Electrochemical Sensors, Electroanalysis. 27 (2015) 1303-1340. doi:10.1002/elan.201400628.

[41] F. Yan, X. Lin, B. Su, Vertically ordered silica mesochannel films: electrochemistry and analytical applications, Analyst. 141 (2016) 3482-3495. doi:10.1039/C6AN00146G.

[42] A. Walcarius, Silica-based electrochemical sensors and biosensors: Recent trends, Curr. Opin. Electrochem. 10 (2018) 88-97. doi:10.1016/j.coelec.2018.03.017.

[43] P. Zhou, L. Yao, K. Chen, B. Su, Silica Nanochannel Membranes for Electrochemical Analysis and Molecular Sieving: A Comprehensive Review, Crit. Rev. Anal. Chem. 0 (2019) 1-21. doi:10.1080/10408347.2019.1642735.

[44] M. Etienne, A. Quach, D. Grosso, L. Nicole, C. Sanchez, A. Walcarius, Molecular Transport into Mesostructured Silica Thin Films: Electrochemical Monitoring and Comparison between p 6 m , P6 3 / mmc , and Pm 3 n Structures, Chem. Mater. 19 (2007) 844-856. doi:10.1021/cm0625068.

[45] T. Nasir, N.A. Vodolazkaya, G. Herzog, A. Walcarius, Critical Effect of Film Thickness on Preconcentration Electroanalysis with Oriented Mesoporous Silica 
Modified Electrodes, Electroanalysis. 31 (2019) 202-207.

doi:10.1002/elan.201800533.

[46] K.P. Singh, M. Kumar, Effect of gate length and dielectric thickness on ion and fluid transport in a fluidic nanochannel, Lab Chip. 12 (2012) 1332-1339. doi:10.1039/c21c20869e.

[47] T. Nasir, G. Herzog, M. Hébrant, C. Despas, L. Liu, A. Walcarius, Mesoporous Silica Thin Films for Improved Electrochemical Detection of Paraquat, ACS Sensors. 3 (2018) 484-493. doi:10.1021/acssensors.7b00920.

[48] N. Vilà, P. de Oliveira, A. Walcarius, I.M. Mbomekallé, pH-modulated ion transport and amplified redox response of Keggin-type polyoxometalates through verticallyoriented mesoporous silica nanochannels, Electrochim. Acta. 309 (2019) 209-218. doi:10.1016/j.electacta.2019.03.119.

[49] M.Y. Chen, M.J. Sailor, Charge-Gated Transport of Proteins in Nanostructured Optical Films of Mesoporous Silica, Anal. Chem. 83 (2011) 7186-7193. doi:10.1021/ac201636n.

[50] M.A. del Valle, M. Gacitua, F.R. Diaz, F. Armijo, J.P. Soto, Electro-synthesis and characterization of polythiophene nano-wires/platinum nano-particles composite electrodes. Study of formic acid electro-catalytic oxidation, Electrochim. Acta. 71 (2012) 277-282. doi:10.1016/j.electacta.2012.04.001.

[51] M.A. del Valle, L.A. Hernandez, A.M. Ramirez, F.R. Diaz, Electrosynthesis of polyquinone nanowires with dispersed platinum nnaoparticles towar formic acid oxidation, Ionics (Kiel). 23 (2017) 191-199.

[52] S. Ahoulou, N. Vilà, S. Pillet, D. Schaniel, A. Walcarius, Non-covalent Immobilization of Iron-triazole (Fe(Htrz) 3 ) Molecular Mediator in Mesoporous Silica Films for the Electrochemical Detection of Hydrogen Peroxide, Electroanalysis. (2019) elan.201900444. doi:10.1002/elan.201900444.

[53] L. Ding, W. Li, Q. Sun, Y. He, B. Su, Gold nanoparticles confined in vertically aligned silica nanochannels and their electrocatalytic activity toward ascorbic acid, Chem. - A Eur. J. 20 (2014) 12777-12780. doi:10.1002/chem.201403426. 
[54] L. Lu, L. Zhou, J. Chen, F. Yan, J. Liu, X. Dong, et al., Nanochannel-Confined Graphene Quantum Dots for Ultrasensitive Electrochemical Analysis of Complex Samples, ACS Nano. 12 (2018) 12673-12681. doi:10.1021/acsnano.8b07564.

[55] Z. Zhou, W. Guo, L. Xu, Q. Yang, B. Su, Two orders-of-magnitude enhancement in the electrochemiluminescence of Ru(bpy)3+, Anal. Chim. Acta. 886 (2015) 48-55. doi:10.1016/j.aca.2015.06.005.

[56] J. Zhang, H. Ding, S. Zhao, D. Jiang, H.Y. Chen, Confined electrochemiluminescence in vertically ordered silica mesochannels for the imaging of hydrogen peroxide released from single cells, Electrochem. Commun. 98 (2019) 38-42. doi:10.1016/j.elecom.2018.11.013.

[57] M.B. Serrano, C. Despas, G. Herzog, A. Walcarius, Mesoporous silica thin films for molecular sieving and electrode surface protection against biofouling, Electrochem. Commun. 52 (2015) 34-36. doi:10.1016/j.elecom.2015.01.010.

[58] Q. Sun, F. Yan, L. Yao, B. Su, Anti-Biofouling Isoporous Silica-Micelle Membrane Enabling Drug Detection in Human Whole Blood, Anal. Chem. 88 (2016) 8364-8368. doi:10.1021/acs.analchem.6b02091.

[59] S.-H. Wu, C.-Y. Mou, H.-P. Lin, Synthesis of mesoporous silica nanoparticles, Chem. Soc. Rev. 42 (2013) 3862. doi:10.1039/c3cs35405a.

[60] J. Cloarec, C. Chevalier, J. Genest, J. Beauvais, H. Chamas, Y. Chevolot, et al., pH driven addressing of silicon nanowires onto $\mathrm{Si} 3 \mathrm{~N} 4$ /SiO 2 micro-patterned surfaces, Nanotechnology. 27 (2016) 295602. doi:10.1088/0957-4484/27/29/295602.

[61] W. Li, L. Ding, Q. Wang, B. Su, Differential pulse voltammetry detection of dopamine and ascorbic acid by permselective silica mesochannels vertically attached to the electrode surface., Analyst. 139 (2014) 3926-31. doi:10.1039/c4an00605d.

[62] C. Karman, N. Vilà, A. Walcarius, Amplified Charge Transfer for Anionic Redox Probes through Oriented Mesoporous Silica Thin Films, ChemElectroChem. 3 (2016) 2130-2137. doi:10.1002/celc.201600303.

[63] M. Etienne, Y. Guillemin, D. Grosso, A. Walcarius, Electrochemical approaches for the fabrication and/or characterization of pure and hybrid templated mesoporous oxide 
thin films: a review, Anal. Bioanal. Chem. 405 (2013) 1497-1512.

doi:10.1007/s00216-012-6334-7.

[64] F. Yan, L. Yao, Q. Yang, K. Chen, B. Su, Ionic Current Rectification by Laminated Bipolar Silica Isoporous Membrane, Anal. Chem. 91 (2019) 1227-1231. doi:10.1021/acs.analchem.8b04639.

[65] A. Goux, J. Ghanbaja, A. Walcarius, prussian blue electrodeposition within an oriented mesoporous silica film: preliminary observations, J Mater Chem. 44 (2009) 66016607.

[66] Y. Guillemin, M. Etienne, E. Aubert, A. Walcarius, Electrogeneration of highly methylated mesoporous silica thin films with vertically-aligned mesochannels and electrochemical monitoring of mass transport issues, J. Mater. Chem. 20 (2010) 67996807. doi:10.1039/c0jm00305k.

[67] X. Lin, Q. Yang, F. Yan, B. Zhang, B. Su, Gated Molecular Transport in Highly Ordered Heterogeneous Nanochannel Array Electrode, ACS Appl. Mater. Interfaces. 8 (2016) 33343-33349. doi:10.1021/acsami.6b13772.

[68] Z. Zhou, W. Guo, L. Xu, Q. Yang, B. Su, Two orders-of-magnitude enhancement in the electrochemiluminescence of $\mathrm{Ru}(\mathrm{bpy}) 32+$ by vertically ordered silica mesochannels, Anal. Chim. Acta. 886 (2015) 48-55. doi:10.1016/j.aca.2015.06.005.

[69] N.A. Carrington, L. Yong, Z.L. Xue, Electrochemical deposition of sol-gel films for enhanced chromium(VI) determination in aqueous solutions, Anal. Chim. Acta. 572 (2006) 17-24. doi:10.1016/j.aca.2006.05.020.

[70] P. Schindler, H.R. Kamber, Die Acidität von Silanolgruppen. Vorläufige Mitteillung, Helv. Chim. Acta. 51 (1968) 1781-1786. doi:10.1002/hlca.19680510738.

[71] R.H. Wopschall, I. Shain, Effects of Adsorption of Electroactive Species in Stationary Electrode Polarography, Anal. Chem. 39 (1967) 1514-1527. doi:10.1021/ac50156a018.

[72] R.G. Compton, E. Laborda, K.R. Ward, UNDERSTANDING Voltammetry :, Imperial College Press, 2013. doi:10.1142/P910.

[73] Y.S. Park, K. Lee, C. Lee, K.B. Yoon, Facile reduction of zeolite-encapsulated viologens with solvated electrons and selective dispersion of inter- and intramolecular 
dimers of propylene-bridged bisviologen radical cation, Langmuir. 16 (2000) 44704477. doi:10.1021/la991430+.

[74] F.M. Hinterholzinger, S. Wuttke, P. Roy, T. Preuße, A. Schaate, P. Behrens, et al., Highly oriented surface-growth and covalent dye labeling of mesoporous metal-organic frameworks, Dalt. Trans. 41 (2012) 3899-3901. doi:10.1039/c2dt12265k.

[75] W. Turbeville, D.S. Robins, P.K. Dutta, Zeolite-entrapped tris(2,2’bipyridene)ruthenium(2+): intermolecular structural and dynamic effects, J. Phys. Chem. 96 (1992) 5024-5029. doi:10.1021/j100191a053.

[76] K. Sakai, E.G. Smith, G.B. Webber, C. Schatz, E.J. Wanless, V. Bütün, et al., pHresponsive diblock copolymer micelles at the silica/aqueous solution interface: Adsorption kinetics and equilibrium studies, J. Phys. Chem. B. 110 (2006) 1474414753. doi:10.1021/jp062830q.

[77] C. Geffroy, M.P. Labeau, K. Wong, B. Cabane, M.A.C. Stuart, Kinetics of adsorption of polyvinylamine onto cellulose, 2000.

[78] J.C. Dijt, M.A. Cohen Stuart, J.E. Hofman, G.J. Fleer, Kinetics of polymer adsorption in stagnation point flow, 1990.

[79] B.L. Schottel, H.T. Chifotides, K.R. Dunbar, Anion- $\pi$ interactions, Chem. Soc. Rev. 37 (2008) 68-83. doi:10.1039/b614208g.

[80] M.J. Sims, N. V. Rees, E.J.F. Dickinson, R.G. Compton, Effects of thin-layer diffusion in the electrochemical detection of nicotine on basal plane pyrolytic graphite (BPPG) electrodes modified with layers of multi-walled carbon nanotubes (MWCNT-BPPG), Sensors Actuators, B Chem. 144 (2010) 153-158. doi:10.1016/j.snb.2009.10.055.

[81] W. Tian, H. Hu, Y. Wang, P. Li, J. Liu, J. Liu, et al., Metal-Organic Frameworks Mediated Synthesis of One-Dimensional Molybdenum-Based/Carbon Composites for Enhanced Lithium Storage, ACS Nano. 12 (2018) 1990-2000. doi:10.1021/acsnano.7b09175.

[82] C. Karman, N. Vilà, C. Despas, A. Walcarius, Indirect amperometric detection of nonredox ions using a ferrocene-functionalized and oriented mesoporous silica thin film electrode, Electrochim. Acta. 228 (2017) 659-666. 
doi:10.1016/j.electacta.2017.01.126. 